\title{
Towards African humanicity. Re-mythogolising Ubuntu through reflections on the ethnomathematics of African cultures
}

\author{
Iman C Chahine \\ University of Massachusetts Lowell, MA, USA \\ Self-Directed Learning Research Unit, North-West University, Potchefstroom, South Africa \\ Corresponding author: Iman_Chahine@uml.edu
}

(Submitted: 9 January 2020; Accepted: 27 July 2020)

\begin{abstract}
Throughout the history of mathematics, Eurocentric approaches in developing and disseminating mathematical knowledge have been largely dominant. Building on the riches of African cultures, this paper introduces ethnomathematics as a discipline bridging mathematical ideas with cultural contexts thereby honoring diversity and fostering respect for cultural heritages. Ethnomathematics promotes a conceptualisation of culture to include the authentic humanity of the people sharing collective beliefs, traditions, and practices. I propose the term African humanicity to refer to the authentic African experience that reflects genuine African cultural identity. I further argue that immersion in the ethnomathematical practices of African cultures provides insight into critical factors shaping African students' success in mathematics. Drawing upon the vast literature on the ingenuity of African cultures, I present ethnomathematical ideas that permeate numerous African indigenous knowledge systems that could be introduced in the mathematics curriculum. These systems include folk games and puzzles, kinship relations, and divination systems.
\end{abstract}

Keywords: African divination systems, African indigenous games, African kinship relations, ethnomathematics, mathematics teaching and learning

\section{Introduction}

Historically, it has been widely confirmed that Africa constitutes the cradle of mathematical and scientific thought (Gerdes, 2014; Marshack, 1991; Rudman, 2007). More recently, archaeological evidence collected from different cultures has unearthed numerous indigenous technologies that inherently embody mathematical structures, such as number systems, folk games and puzzles, kinship relations, divination systems, and symmetric strip decorations (Chahine, 2011). Bogoshi, et al.

This publication is covered by a Creative Commons Attribution 4.0 International license. For further information please see: http://creativecommons.org/licenses/by/4.0/. 
(1987: 294) cite one of the earliest indigenous technologies that is assumed to represent a manifestation of human mathematical activity:

a small piece of the fibula of a baboon, marked with 29 clearly defined notches discovered in the early 1970s during an excavation of Border Cave in the Lebombo Mountains between South Africa and Swaziland and initially dated to approximately 35,000 BC.

The bone resembles the calendar sticks used by Khoe San peoples in South Africa who developed unique visual discrimination and visual memory to adapt and survive amidst harsh conditions of the desert (Anaya, 2010). Such knowledge systems and many others thrive in African contexts and are manifest in areas ranging from cultural and religious ceremonies to agricultural and health interventions (Konadu, 2007). I argue that unearthing the "mathematicality" of African cultures and exploring the interconnectedness between cultural practices and mathematics could broaden mainstream conceptualisation of what counts as mathematics.

This paper reflects on the centrality of ethnomathematics as a discipline bridging mathematical ideas within cultural contexts thereby honoring diversity and promoting respect for cultural heritages (Chahine, 2019; Chahine and Kinuthia, 2013; Cimen, 2014; D'Ambrosio, 1985, 1991; 2001; Gerdes, 1994). From this stance, I maintain that a critical implication of being immersed in ethnomathematical practices is to encourage teachers to be mindful of the fact that children from diverse backgrounds have different modes of thinking. Inspired by Mezirow's (1991) perspective of critical reflectivity in narratives, this paper employs an inclusive, permeable and integrated meaning perspective making use of reflection and rational discourse for validating ethnomathematics as memory engages to reinterpret a lived experience in an African context. It is my hope that such a rhizomatic story and the dynamic interplay of all forms of "antenarratives" explored in this paper can create fertile ground for transformative mathematics education.

Throughout the history of mathematics, the Eurocentric epistemological approaches have been largely dominant. Arguably, such a reality is the birth child of a deeply entrenched historical reduction on the part of the Western world that deliberately marginalised the contributions of many societies in the production of mainstream mathematical knowledge (Chahine, 2019). As a teacher educator and an international scholar in the field of mathematics education for more than three decades in the United States and beyond, I came to believe that as an enterprise reflecting the values and practices epitomized by society at large, education mirrors those social views and behavior patterns that are inherently entrenched and valorised by the culture. This is particularly prevalent in many educational systems around the world, where it is often claimed that integration of schools has opened up avenues of access to quality education to al/ (OECD, 2019). Yet, the realities of racial and socioeconomic isolation and segregation continue to incessantly proliferate, in many disguised forms, educational policies that valorise Western culture and dominant ways of knowing (Kaya and 
Seleti, 2013). The abysmal inequalities that we witness in schools and societies worldwide have helped to create a rather apocalyptic vision for the future of education, one that threatens education functioning as a means for critical engagement and social empowerment (OECD, 2019; RousseauAnderson and Tate, 2008). The South African experience is a poignant reminder of the reality that while a nation persistently scuffles to seek pathways to reduce poverty, inequality remains tenaciously high. According to the 2018 World Bank report on overcoming poverty and inequality, South Africa remains one of the most unequal countries in the world, and where education serves as one of the major contributors to the reportedly high inequality level. In the face of such threats, which transcend national and geographic boundaries, we, as educators, seek refuge and inspiration in antihegemonic curriculum and the perspectives of critical thinkers, who remind us of the ultimate goals of education namely - humanisation and liberation.

In this paper, I draw attention to one epistemological and curricular tale. This tale is about the role of ethnomathematics as pedagogy of humanisation that recognises the contributions of African cultures in the production and diffusion of mathematical knowledge. Ethnomathematics is principled by an ideology that calls for reclaiming cultural identities and redeeming human dignity (D'Ambrosio, 2001). I further maintain that authentic engagement in ethnomathematics praxis permits a deeper understanding of the African conceptualisation of humanity. With heightened emphasis on memorialising the nobility of mathematical practices that emerge in the daily life of African communities, ethnomathematics shifts the gaze from focusing on African intellect as a contextbound social construct to considering a broader emphasis on African acuity as a steering force that monitors the constant reconstruction of cultural identities throughout history. I also argue that immersion in the ethnomathematical practices of African cultures provides an insight into critical factors that can shape African students' success in mathematics.

Drawing upon the vast literature on the ingenuity of indigenous African cultures (Chapman, 2019; Malan, 2016), the study presents a set of ethnomathematical ideas that permeates numerous African indigenous knowledge systems. These systems include folk games and puzzles, kinship relations, and divination systems.

\section{What is ethnomathematics?}

At its inception, ethnomathematics as an epistemology, emerged in response to a longstanding history disclosing a deliberate devaluation of the mathematics developed and expanded by nonEuropean civilizations (Chahine, 2011; Powell and Frankenstein, 2009). Early accounts on the history of mathematics are fraught with chronological and epistemological trajectories depicting mathematics as a creation of Western civilisations that conquered and dominated the entire world. Bishop (1990: 52) described Western mathematics as 'one of the most powerful weapons in the imposition of Western culture'. 
However, new perspectives on the history of mathematics that challenge the "classical" Eurocentric views have recently emerged acknowledging and emphasising the contributions of nonWestern indigenous cultures to the development of science and mathematics (Chahine, 2011; Ernest, 2009; Joseph, 2011). Such metanarratives and discourses legitimise the epistemological vision advanced by ethnomathematics and have inspired many researchers and educators around the globe to recognise the need to demand respect and human dignity for communities on which Western knowledge and values have been imposed.

While a number of contested definitions and associated perspectives are increasingly emerging in the research on ethnomathematics, two overarching conceptualisations determine the orientation and underlying epistemology of the field. D'Ambrosio (1985: 46) defined ethnomathematics as

the mathematics practiced by cultural groups, such as urban and rural communities, groups of workers, professional classes, children in a given age group, indigenous societies, and so many other groups that are identified by the objectives and traditions common to these groups.

Additionally, D’Ambrosio (1999: 150) described ethnomathematics as

a program in history and epistemology with an intrinsic pedagogical action ... taking into account the cultural differences that have determined the cultural evolution of human mankind and political dimensions of mathematics.

In this respect, ethnomathematics draws on the potential of cultures in providing tools for the reconceptualisation of power, thereby reconfiguring the political, epistemological, and practical dimensions of mathematics.

D'Ambrosio (2004) contended that the role of ethnomathematics in education is to: a) foster creativity by helping people capitalise on their potentials and invest in their strengths, and b) advance citizenship by promoting equitable rights and opportunities in society. Barton (2004) further prioritised the need for reconstructing a new historiography of mathematics by humanising the field and reclaiming its ethical and moral legacy toward preserving humanity.

In the cause of humanisation and liberation, ethnomathematics calls for radically revolutionising space, content, and approaches to mathematics education (Maxwell and Chahine, 2013). As an organic model of communal learning and mathematics-identity building, ethnomathematics emphasises the role of the classroom as free, flexible and democratic space for reconfiguring history and empowering students as well as teachers toward the pursuit of truth (Chahine, 2011; Maxwell and Chahine, 2013). In such a space, the privileged voice of authority is deconstructed by collective critical practice and where students are seen as human beings with 
complex lives and diverse experiences, sharing their daring voices in continuous dialogue among each other and with the teacher. Ascher (1991), on the other hand, provides a more 'ideological and polemic' definition by emphasising the mathematical ideas created and perfected by indigenous societies and which are inherently embedded in their social practices and daily rituals. Ascher (2002) further capitalised on the riches and complexity of numerous knowledge systems that reflect the practices of more than 6,000 eminent cultures such as the Inuit, Iroquois, and Navajo of North America; the Incas of South America; and the Bushoong, Kpelle, and Tshokwe of Africa; and many others.

Mukhopadhyay, et al. (2009) cited six broad categories delineating the range of emerging ethnomathematics research in conjunction with the aforementioned definitions. These include research on ethnomathematical contributions from different parts of the world, particularly in Africa (Chahine, 2014; Gerdes, 1994, 1995, 2007, 2009; Zaslavsky, 1973, 1999); informal and out-of-school studies (Carraher, et al., 1985; Hoyles, et al., 2001; Jurdak and Shahin, 1999, 2001; Lave, et al., 1984), and the political and historical context of mathematics (Gerdes, 2008; Joseph, 2011; Struik, 1997).

\section{African "humanicity" and ethnomathematics}

When defining ethnomathematics, D'Ambrosio (2001) cautioned against unintentional attempts to romanticise and exoticise the field. He further advanced ethnomathematics as a system of knowledge that perpetuates an education for peace, citizenry, and reclamation of cultural dignity. As such, ethnomathematics promotes a conceptualization of culture in its widest sense to include the authentic humanity of the people sharing the collective beliefs, traditions, practices, etc. To describe what I mean by authentic humanity, I propose a neologism, humanicity arguing for African humanicity as the authentic African life experiences and encounters that reflect genuine African cultural identity, which transcends erroneous socio-political stereotyping; artificial classifications; and colour supremacy. The notion of humanicity occurred to me during a visit to South Africa in the summer of 2011.

In July of that year, I accompanied a group of students on a study abroad immersion program to KwaZulu Natal province in South Africa as part of a graduate course on Indigenous Mathematical Knowledge Systems, which I was facilitating that summer. The primary purpose of the course is to examine how different cultural groups interpret mathematical concepts in ways that are quite different from what they might expect from typical mathematical texts. The course dovetailed two components: a classwork component where students investigated mathematical ideas inherent in indigenous multicultural mathematics practices such as creating calendars, indigenous art and decoration, divination, numeration systems and counting schemes, as well as indigenous games. Connections between ethnomathematics and mathematics education in schools were also emphasized. The second component involved a cultural immersion experience to engage students in ethnomathematics methodologies. The purpose of the trip was to afford graduate students' 
firsthand experiences to interact with the local residents and to explore the riches of indigenous knowledge systems that thrive in the Zulu culture. During the site visit, students explored the integration of hand and mind tools that indigenous cultures continually employ to plan, conceptualise, visualise, and execute myriad activities as part of their daily practice.

In our everyday encounters with the Zulu speaking people and amidst the flood of quintessentially artistic African treasures that we witnessed in the Zululand province, we learned a very significant notion, which closely resonates with the epistemology and philosophy of ethnomathematics. The Zulu word is ubuntu and it depicts a consummate perspective by the Zulu culture of what it means to be human. In his book No Future without Forgiveness, Tutu (1999) explained:

Ubuntu is very difficult to render into a Western language. It speaks to the very essence of being human. When you want to give high praise to someone we say, "Yu, u nobuntu;" He or she has ubuntu. This means that they are generous, hospitable, friendly, caring and compassionate. They share what they have. It also means that my humanity is caught up, is inextricably bound up, in theirs. We belong in a bundle of life. We say, "person is a person through other people" (in Zulu Umuntungumuntungabanye). I am human because I belong, I participate, and I share. A person with ubuntu is open and available to others, affirming of others, does not feel threatened that others are able and good; for he or she has a proper self-assurance that comes with knowing that he or she belongs in a greater whole and is diminished when others are humiliated or diminished, when other are tortured or oppressed, or treated as if they were less than who they are (cited in Lewis, 2010, p.70).

I propose the term African humanicity as a synonym to ubuntu. Both terms connote a conceptualisation of what it means to be human in an African perspective. To this end, ubuntu is absolutely relevant to people of African descent, as well as to any group of people, as it empowers them toward celebrating their identities by challenging the deficit discourses that encourage demarcation and discrimination. Lewis (2010) asserted that reclaiming African heritage and affirming cultural identity can be realized through the pursuit of ubuntu, which in turn, empowers African youth to maintain a positive belief in their ability toward academic success and exceptional performance. More importantly perhaps is the insight that ubuntu offers in understanding the physics of Blackness and the role that identity plays in conceptualising African students' academic success.

In exploring the brilliance of African students as mentioned elsewhere (Chahine, 2013), I argue that it is essential to understand the nature of African humanicity, to delve deeper into the essence of blackness and what it really means to be Black. Grounded in the belief that the concept of blackness extends beyond the physicality of skin colour and phenotypical characteristics, African 
humanicity concurs with Lartey's (cited in Lewis, 2010: 73) suggestion that 'by Black we refer in a general sense to people of African, Caribbean and Asian descent as well as people who identify with "the Black experience" in terms of heritage, oppression and domination'. In this respect, D'Ambrosio (2001: 28) asserts

The fundamental strategy in the process of conquest adopted by a [dominant] individual, group, or culture, is to maintain the other [dominated] individual, group, or culture, in an inferior position. One very efficient way to keep an individual, group, or culture inferior is to weaken their roots, removing the historical ties and historicity of the dominated. This is the most effective way to carry out a conquest.

Admittedly, societal inequities basically emerge as a result of failing to pass the discriminatory barriers established by the dominant glitterati, including, and principally, the school system. Yet there is an immediate politics of what counts as doing "academic" mathematics skillfully, which lies in children getting it or not-a politics of going-on together in a particular time and place. If the way children "do" mathematics is not in sync with the "officially sanctioned" Eurocentric rationalism dominating the mathematics school curricula worldwide, if it does not pass by those that matter here and now, then children are deemed to have commanding problems to deal with. However, Spengler (cited in D'Ambrosio, 2001: 7) reminds us that

there is no single mathematics; there are many mathematics. What we call "the" history of mathematics -a supposed progressive approximation to a single immutable ideal-becomes, in reality, once the deceiving image of the surface of history is dismissed, a plurality of independent processes, complete in themselves; a sequence of births of worlds of forms, new and distinct.

\section{The Role of Ethnomathematics in the Classroom}

The myth that mathematics can be taught effectively and meaningfully without relating it to students' culture has been widely destabilised and dispelled. This claim is supported by a handful of research that has shown the importance of ethnomathematics approaches to integrating cultural practices that resonate with students' ethnic background and everyday experiences. Similarly, Murrell (2007: 34) contended that student achievement is an activity occurring within a community, and that 'school success is achievable for all students when learning is understood as the acquisition of a set of preferred cultural practices' and as we come to see teaching and learning as the 'socialisation of these cultural practices in educational settings'.

Additionally, there have been many success stories in the literature that report enhanced performance when cultural practices from ethnomathematics are integrated in the mathematics 
instruction. In a study in the United States which investigated the effect of using African culture on African American students' achievement in geometry, Moses-Snipes (2005) implemented ethnomathematics practices with 107 fifth-grade students in a public elementary school. Classes were randomly assigned to either the Mathematics with Culture (MWC) group or the Mathematics without Culture (MWOC) group. The mathematics lessons lasted approximately 120 minutes for both groups. Both groups completed an entire geometry unit created by the researcher. The MWC group completed the geometry unit with some facet of African culture integrated into each activity. The MWOC group completed the same unit without the African culture component. Results of the study showed that students' achievement scores increased as they learned about African culture. Moses-Snipes (2005: 159) established that:

The implementation of culture in the mathematics classroom should be researched from the first-year students enter school in order to obtain a true sense of cultures' effect on mathematics achievement throughout students' schooling.

In a similar vein, Scott (2018) found that African American high school students had a high sense of racial awareness and cultural pride when engaged in learning ethnomathematics using culturally relevant pedagogies. Generally, the students felt that the incorporation of culture into mathematics scaffolded their understanding and enhance their motivation. In a similar study, Ensign (2003) described the efforts of integrating personal, everyday practices of students into classroom mathematics in an urban school setting. The author described the culturally related technique of teaching as culturally connected, which was aimed at finding creative and meaningful problems that helped to mediate the difficulty that students face in understanding mathematical concepts.

There is ample evidence in the literature supporting the claim that culture can be implemented in the mathematics classroom in various ways and with a wide range of varying resources. Kim (2000) proposed two ways to integrate ethnomathematics in the process of teaching and learning in the mathematics classroom: first, through the use of inventive ideas inspired from one's own culture; second, by the exploration of new ideas in other cultures. Kim (2000) also emphasised the role that ethnomathematics materials play in the enculturation and acculturation processes within and across diverse cultures. Capitalising on the riches of the African cultures and building on the ingenuity of Black people empowers African American students toward success in mathematics by providing meaningful and relevant contexts conducive to learning to further the achievement of students, particularly those from underserved populations.

\section{Traditional African and African American Games}

Research on the ethnomathematics of African cultures has provided a wealth of creative and thought provoking African mathematics such as number systems (Zaslavsky, 1973), indigenous games and 
puzzles (Laridon, et al., 2005), kinship relations (Ascher, 1991), divination systems (Chahine, in press; Eglash, 1995), symmetric strip decorations (Gerdes, 1995; 1999; 2007; 2009), and many others that can be actively used by students in the classroom to enhance their learning. Ascher (2002) argues that what makes culturally derived mathematical ideas so powerful is their inherent entrenchment in contexts in which they arise as part of the complex of ideas around them.

One of the most prolific cultural artefacts that unfold the creativity and rigour of the African heritage are games. It is interesting to note that while African games were initially discouraged by the colonial education authorities in favour of European originated games such as ludo, snakes and ladders (Zaslavsky, 1999), such games fervently persist in the daily life of indigenous African communities. Powell and Frankenstein (1997: 249) asserted that '[i]n classrooms, ethnomathematics can be implemented by investigating the mathematics of cultural products and practices, such as games, with people from that culture or by exploring the mathematics of a different culture to help students enrich their construction of mathematical ideas'. Kim (2000) cited more than 200 traditional games that are inspired from African cultures, and Bayeck (2018) examined the role of African board games, such as Oware (Ghana), Bao (East Africa), Moruba and Morabaraba (South Africa), Omweso or Mweso (Uganda), in enhancing the learning of mathematics concepts. Similarly, Ejuu (2019) averred that African indigenous games emblematise heritage, pedagogy and practice conceivably forging the African identity of respective communities.

In addition to having a positive influence on the affective or emotional component of learning situations (Booker, 2000) and raising levels of students' interest and motivation (Bragg, 2007), African indigenous games embody several mathematical concepts including Boolean logic, experimental and theoretical probabilities as well as high order cognitive skills such as decision making, problem solving and critical thinking. The power of games in teaching rests in their ability to motivate learning and provide tools that bring into play many cognitively challenging strategies that hone students' mathematical skills. Van Binsbergen (1999) argued that games comprise a collection of mathematical investigations such as riddles, networks, arrangements, probability and chance, etc. Powell and Temple (2001: 369) claimed that when playing games, children develop '...intellectual frameworks that enable them further to construct and comprehend complex mathematical ideas, strategies, and theories'. For example, Mancala is an African board game that is played worldwide with more than 20 different versions. The two-row versions include oware (Ghana), awélé (Ivory Coast), and ayo and okwe (Nigeria), and the four-row versions, omweso (Uganda), and tshisolo (Zaire) (Crane, 1982).

Powell and Temple (2001) capitalised on the potential of oware board game in building and extending arithmetical ideas, thus, scaffolding strategic thinking. The wari or oware is played by the Asante people of Ghana on a board with two rows of six holes and an additional hole or pot at each end (See Figure 1). 


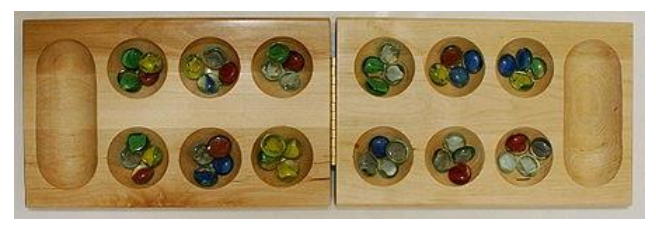

Figure 1: Oware game board played in Ghana

The two players face each other and begin by placing four seeds in each of six holes. The object of the game is to capture at least 25 seeds (a majority of the total of 48 ) into one's pot. When the opponent's hole has been cleared or has only one seed, the game has ended. Zaslavsky (1999) explained that another version of the game that is played in Uganda is called omweso or mweso and the game involves a four-row board and requires 64 beans on a board having four rows of eight holes (see Figure 2).

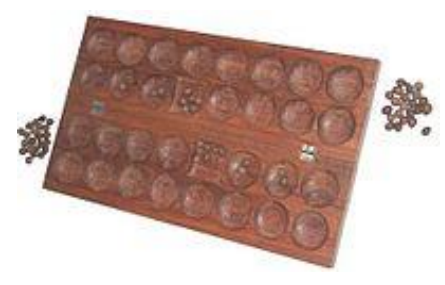

Figure 2: Omweso board game played in Uganda

This game encourages children to count, and learn simple sums, as well as the concept of oneto-one correspondence as they drop each of their counters into consecutive holes. Omweso also permits reverse moves introducing the concept of negative numbers. Furthermore, students can establish connections between theoretical and experimental probabilities, theoretical probability as the ratio of the number of ways a certain event can occur to the number of possible outcomes, while experimental probability is based on an experiment and is represented as a ratio comparing the number of times the event occurred to the number of trials.

Many of the African traditional board games can be played using organic materials found in nature, such as seeds and stones. Boards can be scratched into dirt, dug out of the ground or drawn on paper (see Figure 3). 


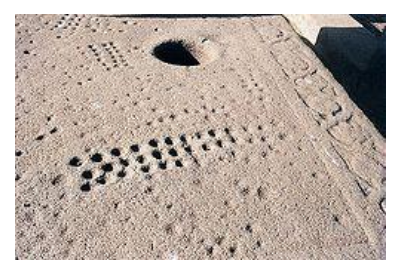

Figure 3: Ancient Mancala board engraved in the sand

\section{African kinship relations}

The concept of kinship relationships represents a formalised body of knowledge that can be intimately tied to mathematical structures. Anthropological research is laden with advanced mathematical networks and models that employ graph theory to solve and explain a range of culturally specifc relations. Using mathematical models to understand the wide range of kinship terminologies that exist in indigenous communities around the world yields a variety of new insights into the social structure and organisation of various cultures. The Gada system of the Borana, a pastoral community, who lives in the Sidamo province of Ethiopia and Southern Kenya is one interesting example of African kinship structure that involves formal linear and cyclic configurations. Gada is a generation-grading system that is characterised by the rule that all sons follow their fathers in a sequence of grades at a fixed and specific interval irrespective of their actual age. Ascher (2002: 142) explains that '[b]asic to the Gada system are consecutive grades, through which, theoretically, all males pass, and named classes, which refer to those who are in the grades'.

The Borana people invented the basic principles of the system, which is a spiral of 10 grades each of 8 years duration and 7 class names, structured in a way that boys in the first grade are the sons of men in the sixth grade; those in the second grade are sons of men in the seventh grade, etc. Using Ascher's (2002) configuration, the relationship between father and son can be represented through modular algebra notation by the following equation:

$S^{n}\left(c_{i}\right)=c_{i-5 n(\bmod 7)}$ for $\mathrm{n}=1,2, \cdots_{. ;} ; \mathrm{i}=1,2,3,4,5,6,7$, where $\mathrm{S}\left(\boldsymbol{c}_{\boldsymbol{i}}\right)$ is the father of $\boldsymbol{c}_{\boldsymbol{i}}$.

Ascher(2002) further explained that the father-to-son descent cycle can be modeled by a permutation transforming the name cycle into the father-son cycle by interchanging $c_{i}$ with

$c_{2 i+1(\mathrm{mod})}$ (p. 149). Legesse (1973) argues that the Borana uses the terms, gogessa or the 5-name patri-class, and makabasa for a cycle of seven names for the purpose of ordering the Borana chronology and to delineate the historical map of their society.

Mathematical ideas inspired by the logic underlying African kinship relations can enrich and invigorate the learning of mathematics by affording Black students the means to participate in African humanicity. It is important to note that in examining kinship relations across many cultures 
the emphasis is not on the mathematical principles involved per se but rather on the use of mathematics as classificatory and descriptive typology to understand the genealogical relationships and internal organisation of sophisticated cultural and social systems. As Hage and Harary (1983: 68) note in their analysis of Arapesh sexual symbolism:

Mathematical models are used not because of any wish to mathematise culture but because there are ethnographic advantages for doing so. The general advantage of group models is that they preserve and exploit the richness of the data rather than obliterating it through generalisations.

To Goethe we owe this inspired ordering, which he called The Idea, of which the form is immediately apprehended in the domain of intuition. Whereas pure science does not apprehend but observes and dissects, ethnomathematical methods go beyond observation and dissection, and in its highest moments finds the way by vision, not abstraction. Therefore, I argue, that engaging students in exploring the logical structures of diverse kinship systems and family relationships within indigenous communities sensitises students to understand the role that mathematics plays in capturing the many ways through which culture as a complex system self-organises and preserves its practices.

\section{African divination systems}

The role of African divination systems is pivotal not only in understanding the epistemology of African Peoples and their cultures but also to unfold the extensive body of indigenous knowledge embedded in those practices (Chahine and Kinuthia, 2013). Eglash (1997) investigated the mathematically significant aspect of doubling in African religion that occurs in the divination techniques of Bamana. He described the technique of Ifa as purely stochastic (i.e. operates by pure chance) and that of Bamana as systematic, highly compact oracles which follow laws of recursion.

Ascher (2002) also introduced a twin of the Bamana technique 5,000 miles to the east in Malagasy Sikidy. The rich available literature presents ample evidence that these major African divination systems were all transformations of the Arabic system of 'Sand Science' (i/m al-raml) or 'Sand Calligraphy' (khatt al-raml) which spread from Abbasid, Iraq, all over the Islamic world, the Indian Ocean region, and Africa from the late first millennia Common Era (CE) ${ }^{1}$ onwards (Chahine, in press). Partly rooted in simple chance procedures (like hitting the earth, throwing tablets, beans, shells, etc.), the Bamana system is a binary system of 16 figures where each figure is 4 rows high and each row consists of either one dot or two dots. The figures are determined through various methods both ancient and modern. The procedure is performed through a forceful hitting of the sand with a

\footnotetext{
${ }^{1}$ Common Era also known as Current Era or Christian Era, abbreviated as CE and is traditionally identified with Anno Domini (abbreviated AD).
} 
stick, in order to produce a chance number of dot traces or marks, which can then be scored as either odd or even.

Divination systems are dynamic systems that reflect patterns of social interactions, the community's identity and cognitive processes indicative of the people's ways of thinking. Engaging students in exploring these complex routines and the mathematical structures inherent in their design will provide an insight into mathematics as a human endeavor.

\section{Toward a new paradigm}

There is no doubt that affording students the opportunities to explore the mathematical ideas of Africa and other cultures in the classroom is crucial for understanding the hegemonic misrepresentations and deliberate devaluation of those cultures (Alatas, 1978; Joseph, 2011; Said, 1978). I have argued that allowing purposeful engagement in existential experiences that unfold culturally embedded mathematical competences can inspire students to question enforced imminent boundaries and rediscover the joy and excitement in making transformation real and possible.

A deeper and more insightful examination of numerous valuable and unique contributions of the African cultures in the production and dissemination of mathematical knowledge has great potential in dismantling the arguments against the brilliance of African students in mathematics and, thus, silence the mythical stereotyping regarding the intellectual representation of African people. Implicit in the extensive role of Western mathematics in academic institution and industries is the deliberate utilisation of the field as a tool to assert the cultural superiority of Europeans thereby marginalising the mathematical heritage of African cultures. I concur with Bangura's (2012: 3) view that ' $\mathrm{t}$ ] $\mathrm{o}$ Eurocentric scholars, even the Africanity of Egyptian mathematics is often denied. But contrary to the popular Eurocentric view, one can neither racially nor geographically separate Egyptian civilisation from its Black African roots'. As such, recognising the contributions of African cultures to the edifice of mathematical knowledge, albeit belated, encourages broader and deeper reflections about the design of teacher training programs in Africa. Beyond the vision of preparing teacher-practitioners as engaged and networked communities of practice skilled in creating interdisciplinary educational experiences to solving grand challenges, it is equally important to capacitate teachers with socially just teaching approaches that support meaningful learning, and this is not a superficial quest, it is a human-rights endeavor. Therefore, sensitising African students to the inventions and contributions of African mathematicians in the context of African humanicity, is essential to highlight the richness of African cultural experiences affording opportunities to challenge and thereby dispute the Eurocentric view of what counts as mathematical knowledge and how to teach it to children. Needless to say, such understanding is necessary to question the veracity of claims about Black achievement in mathematics. Enriching classroom instruction with ethnomathematical investigations inspired from African cultures and indigenous knowledge systems 
can inform, enlighten, and reconfigure the overly skewed representation of African students' ability in mathematics. Indeed, keeping the focus on mathematics as a human endeavor and celebrating cultural diversity are key dimensions for enacting pedagogies of transformation, liberation, and transgression.

\section{Author Biography}

Iman Chahine is an Associate Professor at University of Massachusetts Lowell and Research Fellow in Self-Directed Learning Unit at North West University, South Africa. She is also a Fulbright US Scholar in South Africa, co-editor of Journal of Mathematics \& Culture and Treasurer of International Study Group on Ethnomathematics (ISGEm).

\section{References}

Alatas, S.H. 1978. Myth of the Lazy Native. London, UK: Frank Cass and Company Limited. Anaya, J. 2010. The Situation of Indigenous Peoples in Botswana. United Nations, A/HRC/15.

Ascher, M. 1991. Ethnomathematics: A Multicultural View of Mathematical Ideas. Pacific Grove, CA: Brooks/Cole.

Ascher, M. 2002. Mathematics Elsewhere: An Exploration of Ideas Across Cultures. London, UK: Princeton University Press.

Barton, B. 2004. Moving forward. Proceedings of the 10th International Congress of Mathematics Education Copenhagen.

Bayeck, R.Y. 2018. A review of five African board games: Is there any educational potential? Cambridge Journal of Education, 48(5): 533-552.

Bishop, A. 1990. Western mathematics: The secret weapon of cultural imperialism. Race \& Class, 32(2): 51-56.

Booker, G. 2000. The Maths Game: Using Instructional Games to Teach Mathematics. Wellington, NZ: New Zealand Council for Educational Research.

Bragg, L. 2007. Students' conflicting attitudes towards games as a vehicle for learning mathematics: A methodological dilemma. Mathematics Education Research Journal, 19(1): 29-44.

Carraher, T.N., Carraher, D.W. \& Schliemann, A.D. 1985. Mathematics in the streets and in schools. British Journal of Developmental Psychology, 3: 21-29.

Chahine, I.C. 2011. Beyond Eurocentrism: Situating ethnomathematics within the history of mathematics narrative. International Journal for Studies in Mathematics Education, 4(2): 35-48.

Chahine, I.C. 2013. Ethnomathematics in the classroom. In Martin, D.\& Leonard, J. (eds.) The Brilliance of African American Students in Mathematics. Charlotte, NC: Information Age Publishing.

Chahine, I.C. 2014. Investigating ethnomathematics and indigenous mathematical knowledge systems through cultural immersion. In Berlin, D.F. \& White, A.L. (eds.) Initiatives in 
Mathematics and Science Education with Global Implications. Columbus, $\mathrm{OH}$ : International Consortium for Research in Science and Mathematics Education.

Chahine, I.C. 2019. Investigating students' perceptions of indigenous mathematical knowledge systems through immersion in transcultural settings. In Shockey T. (ed.) Culture that Counts. Galena, OH: White Plum Publishing, 519-530.

Chahine, I.C. in press. IIm Al-raml: A case study in mathematizing divination systems using modular arithmetic. The Oriental Anthropologist Journal.

Chahine, I.C. \& Kinuthia, W. 2013. Juxtaposing form, function, and social symbolism: An ethnomathematical analysis of indigenous technologies in the Zulu culture of South Africa. Journal of Mathematics and Culture, 7(1): 1-30.

Chapman, S. 2019. There is ingenuity in Africa: The architect that builds with trash. The Guardian, 22 October. Available at: https://www.theguardian.com/cities/2019/oct/22/ingenuity-southafrica-architect-kevin-kimwelle-builds-with-trash (accessed 14 December 2019)

Cimen, O.A. 2014. Discussing ethnomathematics: Is mathematics culturally dependent? ProcediaSocial and Behavioral Sciences, 152: 523-528.

Crane, L. 1982. African games of strategy, a teaching manual. African Outreach Series 2. UrbanaChampaign: University of Illinois, 1-63.

D'Ambrosio, U. 1985. Ethnomathematics and its place in the history and pedagogy of mathematics. For the Learning of Mathematics, 5: 44-48.

D'Ambrosio, U. 1999. Literacy, matheracy, and technocracy: A trivium for today. Mathematical Thinking and Learning, 1(2): 131-153.

D'Ambrosio, U. 2001. Etnomatemática: Elo entre as tradições e a modernidade [Ethnomathematics: Link between tradition and modernity]. Belo Horizonte, MG: Autêntica.

D'Ambrosio, U. 2004. Preface. Proceedings of the 10th International Congress of Mathematics Education Copenhagen.

Eglash, R. 1995. Africanisms in American mathematical and information sciences. Available at:http://www.math.buffalo.edu/mad/special/eglash.africanisms-in-math.html $\quad$ (accessed 6 November 2019).

Eglash, R. 1997. Bamana sand divination: Recursion in ethnomathematics. American Anthropologist, 99(1): 112-122.

Ensign, J. 2003. Helping teachers use students' home cultures in mathematics lessons: Developmental stages of becoming effective teachers of diverse students. In Rodriguez, A.J. \& Kitchen, R.S. (eds.) Preparing Mathematics and Science Teachers for Diverse Classrooms: Promising Strategies for Transformative Pedagogy. Mahwah, NJ: Lawrence Erlbaum Associates, Publishers, 225-242.

Ejuu, G. 2019. African indigenous games. Journal of Psychology in Africa, 29(4): 319-327. 
Ernest, P. 2009. The philosophy of mathematics, values, and Keralese mathematics. In Ernest, P., Greer, B. \& Sriraman, B. (eds.) Critical Issues in Mathematics Education. Charlotte, NC: Information Age Publishing Inc, 189-204.

Gerdes, P. 1994. Sona geometry: Reflections on the sand drawing tradition of peoples of Africa south of the equator. Maputo: Universidade Pedagogica.

Gerdes, P. 1995. Women and Geometry in Southern Africa. Universidade Pedagogica, Ethnomathematics Project.

Gerdes, P. 1999. Geometry from Africa: Mathematical and Educational Explorations. The Mathematical Association of America.

Gerdes, P. 2007. Drawing from Angola: Living Mathematics. Maputo, Mozambique: CEMEC.

Gerdes, P. 2009. Introducing Paulus Gerdes' Ethnomathematics Books. Maputo, Mozambique: CEMEC.

Gerdes, P. 2014. Mathematics Education in Mozambique. Maputo, Mozambique: CEMEC.

Hoyles, C., Noss, R. \& Pozzi, S. 2001. Proportional reasoning in nursing practice. Journal for Research in Mathematics Education, 32(1): 4-27.

Hage, P. \& Harary, F. 1983. Structural Models in Anthropology. Cambridge, UK: Cambridge University Press.

Joseph, G.G. 2011. The Crest of the Peacock: Non-European Roots of Mathematics $\left(3^{\text {rd }}\right.$ ed. $)$. New Jersey: Princeton University Press.

Jurdak, M. \& Shahin, I.C. 1999. An ethnographic study of the computational strategies of a group of young street vendors in Beirut. Educational Studies in Mathematics, 40(2): 155-172.

Jurdak, M. \& Shahin, I.C. 2001. Problem solving activity in the workplace and the school: The case of constructing solids. Educational Studies in Mathematics, 47: 297-315.

Kaya, H. \& Seleti, Y. 2013. African indigenous knowledge systems and relevance in South Africa. The International Education Journal: Comparative Perspectives, 12(1): 30-44.

Kim, S.H. 2000. Development of materials for ethnomathematics in Korea. In Selin, H. (ed.), Mathematics Across Cultures. Dordrecht, The Netherlands: Kluwer Academic Press, 455-465.

Laridon, P., Mosimege M. \& Mogari D. 2005. Ethnomathematics research in South Africa. In Vithal, R., Adler, J. \& Keitel, C. (eds.) Researching Mathematics Education in South Africa: Perspectives, Practices and Possibilities. Pretoria: HSRC Press.

Lave, J., Murtaugh, M. \& Rocha, O. 1984. The dialectic of arithmetic in grocery shopping. In Rogoff, B. \& Lave, J. (eds.) Everyday Cognition: Its Development in Social Context. Cambridge, MA: Harvard University Press, 67-94.

Legesse, A. 1973. Gada. New York, NY: Free Press.

Lewis, B. 2010. Forging an understanding of black humanity through relationship: An ubuntu perspective. Black Theology, 8(1): 69-86.

Malan, J. 2016. Innovative ways to teach the youth lessons from South Africa's historical 
legacies. Yesterday and Today, 15: 116-124. Available at: <http://www.scielo.org.za/scielo.php?script=sci_arttext\&pid=S222303862016000100008\&lng=en\&nrm=iso>. ISSN 2309-9003 (accessed 3 January 2020).

Maxwell, K. \& Chahine, I.C. 2013. Cultural immersion and mathematics teacher education: Explorations in Morocco and South Africa. Journal of Humanistic Mathematics, 3(2): 62-75.

Mezirow, J. 1991. Transformative Dimensions of Adult Learning. San Francisco, CA: Jossey-Bass.

Moses-Snipes, P. 2005. The effect of African culture on African American students' achievement on selected geometry topics in the elementary mathematics classroom. Negro Educational Review, 56 (2\&3): 147-166.

Mukhopadhyay, S., Powell, A. \& Frankenstein, M. 2009. An ethnomathematical perspective on culturally responsive mathematics education. In Greer, B., Mukhopadhyay, B.S., Nelson-Barber, S. \& Powell, A. (eds.) Culturally Responsive Mathematics Education. New, York, NY: Taylor and Francis, 65-84.

Murrell, P. 2007. Race, Culture, and Schooling: Identities of Achievement in Multicultural Urban Schools. New York, NY: Routledge.

Organization for Economic Cooperation and Development (OECD) (2019). Rethink policy for a changing world. OECD Publishing. Available at: https://www.oecd.org/economic-outlook/ (accessed 4 January 2020).

Powell, A. \& Frankenstein, M. 2009. Ethnomathematics: Challenging Eurocentrism in Mathematics Education. New York, NY: State University of New York Press.

Powell, A. \& Temple, O. 2001). Seeding ethnomathematics with Oware: Sankofa. Teaching Children Mathematics, 7(6): 369-374.

Rousseau-Anderson, C. \& Tate, W. 2008. Still separate, still unequal: Democratic access to mathematics in U.S. schools. In English, L.D. (ed.) Handbook of International Research in Mathematics Education. New York, NY: Taylor \& Francis, 299-318.

Said, E. 1978. Orientalism. New York and London: Vintage.

Struik, D.J. 1997. Marx and Mathematics. In Powell, A.B. \& Frankenstein, M. (eds.) Ethnomathematics: Challenging Eurocentrism in Mathematics Education. Albany: State University of New York.

Tutu, D. 1999. No Future without Forgiveness. New York, NY: Random House, Inc.

van Binsbergen, W. 1999. Board-games and Divination in Global Cultural History: A Theoretical, Comparative and Historical Perspective on Mankala and Geomancy in Africa and Asia - Part II. Available at: http://www.shikanda.net/ancient_models/gen3/mankala/ mankala1.htm (accessed 17 September 2019).

Zaslavsky, C. 1973. Africa Counts. Boston, MA: Prindle, Weber \& Schmidt.

Zaslavsky, C. 1999. Africa Counts: Number and Pattern in African Cultures. Chicago, IL: Lawrence Hill. 